\title{
Dental Care for the Differently Abled Children in India- The Need of the Hour
}

\author{
Gayathri Krishnan* \\ Pedodontist, India \\ *Corresponding author: Gayathri Krishnan, Pedodontist, Kerala, India

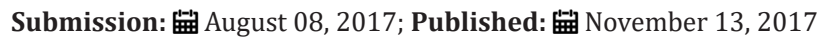

\section{Opinion}

My opinion is aimed to throw light on what we, as pedodontists, can do to provide better oral care for disabled children, what we are doing and what we can contribute to, in the future, for the same.

\section{Why Should We Do It?}

a) Higher prevalence of oral diseases in differently abled children.

b) The Government of India in 2012 has passed the Rights of Persons with Disabilities Bill which states that denying treatment for such persons by any health care professional is punishable.

c) Above all, we have ethical and moral obligations to provide treatment to the needy without any discrimination.

\section{What is the Present Scenario?}

In the state of Kerala in India, there are about 25 dental colleges, branches of the Indian Dental Association and numerous NonGovernmental Organisations (NGOs) which conduct dental camps in special schools. Telephonic enquiries were done to almost 120 special schools/rehabilitation centres throughout Kerala. Dental camps were conducted or are being conducted in almost all the special schools but the vast majority of these camps are confined to mere routine dental check-ups. They don't go a step beyond to provide treatment to those who are in need. Does this change anything?? No.

What are the Main Hurdles we Face in Providing Treatment to Such Children?

These are insufficient funds, insufficient time, lack of experience in treating such children, lack of equipments or access to facilities such as General Anesthesia or conscious sedation and lack of awareness among parents/caretakers that dental issues need to be

redressed promptly to enable such children to pursue a healthy life. But when the path is not defined, you make your own path if you are determined to bring about the change you wish.

\section{What all Can We Do?}

i. Give oral hygiene instructions to parents \& caregivers.

ii. Use educational applications/apps to instruct parents and even children on proper oral care.

iii. As a boon of the connected world, make use of teledentistry to share information across remote places.

iv. Encourage dental institutions to provide mobile dental vans to be taken to the special schools in the respective area and provide at least the bare minimum treatments like oral prophylaxis and Alternative Restorative Treatment (ART). Make arrangements for transportation of those kids who require further dental treatment to the dental institutions.

v. Gather funds from NGOs, IDA or any non-profitable charitable organizations.

vi. You can even volunteer to work with the NGOs in the country by just registering with the National Trust for Welfare of Persons with Autism, Cerebral Palsy, Mental Retardation and Multiple Disabilities run by the Ministry of Social Justice \& Empowerment, Government of India.

vii. Include more methods of training and opportunities to treat special children in the under graduate curriculum.

All these strategies when put into action, can bring about a change for the better. As the famous saying by Mahatma Gandhi goes, "Understanding the difference between what we do and what we are capable of doing, would suffice to solve most of the world's problems". 